\title{
REDAÇÃO JURÍDICA OBJETIVA: O JURIDIQUÊS NO BANCO DOS RÉUS ${ }^{1}$
}

\section{Plain writing in Legal texts: Legalese in the defendant's bench}

\section{Luciane Fröhlich ${ }^{2}$}

Resumo: Autores de documentos jurídicos pecam repetidamente ao não fornecerem estrutura textual e vocabular satisfatória para o completo entendimento de seus textos, aceitando o perigo de serem mal compreendidos pelo leitor final. De fato, de um lado, o bacharelismo produz verborragia e, de outro, minimaliza-se com o uso de siglas e expressões reduzidas (jargão profissional). $\mathrm{Na}$ prática, essas estratégias não são eficazes, prejudicando uma comunicação clara, objetiva e, portanto, unívoca. Dentro desse contexto, parece prudente repensar o uso de certos hábitos linguísticos (formadores de juridiquês), orientando-se à diminuição de barreiras linguísticas entre os agentes de diálogo (operadores do Direito e público

\begin{abstract}
Authors of legal documents often fail to provide satisfactory textual and word structure for the complete understanding of their texts, taking the risk of being misunderstood by readers. From one side, the Brazilian legal language makes use of wordiness and, from another side, it employs minimalist expressions (professional jargon) that render it unreachable for ordinary readers. In practice, these strategies are ineffective as they impair a clear, objective, and unambiguous communication. In this context, we believe that such linguistic habits (know as legalese) must be reconsidered in order to reduce the language barriers that currently exist between the dialogue agents:
\end{abstract}

1 Contém parte dos estudos da tese da autora, defendida em 2014 (PGET/UFSC).

2 Linguista Forense, doutora em Estudos da Tradução (alemão), membro do grupo de pesquisa em Linguística Forense da UFSC, com pesquisa pós-doc voltada à redação jurídica objetiva (Plain Language). E-mail: luciane@i-trad.com 
leigo). Apoiando essa causa, o presente artigo apresenta algumas sugestões, ancoradas em reflexões do movimento internacional Plain Language, que contribuem para uma redação jurídica mais objetiva.

Palavras-chave: Linguística forense. Juridiquês. Plain language. jurists and the general public. The suggestions presented in this article are anchored in reflections on the international movement Plain Language, which targets an objective legal writing.

Keywords: Forensic Linguistics. Legalese. Plain Language.

\section{INTRODUÇÃO}

Few professions are as concerned with language as is the law.

(TIERSMA, 1993)

A epígrafe acima justifica a atenção ao estudo da linguagem como sendo a matéria-prima do Direito, uma vez que "poucas profissões preocupam-se tanto com a linguagem quanto o Direito”. (TIERSMA, 1993). De certa forma, o Direito e a linguagem se confundem, uma vez que é por meio da linguagem jurídica, principalmente a escrita, que a doutrina, a jurisprudência e a legislação, não somente são compartilhadas, como tornam-se legítimas (NUNES, 2006).

No artigo "Documentação Jurídica: reflexões sobre a função social do documento legislativo”, Torres e Almeida (2013) argumentam que "cada uma das fontes do Direito produz, de forma peculiar, informação. E para que esta informação possa ser comunicada, é necessária sua materialização em um documento" (TORRES; ALMEIDA, 2013). Dessa forma, um texto com informações jurídicas torna-se um documento jurídico, aqui definido como sendo um "conjunto de espécies documentais geradas pelo e/ou para o Direito", que "diz respeito às relações jurídicas existentes entre os indivíduos ou destes para com o Estado e vice-versa". (NASCIMENTO; GUIMARAES, 2004 apud TORRES; ALMEIDA, 2013). 
Torres e Almeida (ibidem) ressaltam que os documentos jurídicos são comumente divididos em três categorias: doutrina (ensino), jurisprudência (julgamento) e legislação (lei). Esta categorização contribui para a exploração linguística de documentos jurídicos, uma vez que auxilia, mesmo que parcialmente, na delimitação do alcance legal/linguístico de cada um (FRÖHLICH, 2014).

Por certo, documentos jurídicos são dotados de textos com características especiais e objetivos distintos (com a finalidade discursiva de instruir, julgar, normatizar), situações nas quais diferentes gêneros ${ }^{3}$ (gênero "livro", gênero "sentença", gênero "lei" etc.) conferem identidade à linguagem do Direito. Não obstante, sob a perspectiva da textualidade jurídica como manifestação semiótica, Eduardo Bittar (2010), em sua obra "Linguagem jurídica", vai além dessa caracterização do discurso jurídico. Ele contribui com a matéria classificando os discursos jurídicos em quatro categorias (normativo, decisório, burocrático e científico). Nesse sentido, ele acrescenta o discurso burocrático à classificação de Torres e Almeida (2013). Essa categorização é sustentada pela semiótica jurídica, que, por sua vez, debruça-se sobre as práticas jurídico-textuais. Para Bittar, o discurso burocrático remete-se à linguagem utilizada nas relações jurídicas, fundada na prática institucional e tendo o Estado como protagonista, com características neutras, sem interferências ideológicas (BITTAR, 2010).

Com base nesse cenário, este trabalho discute particularidades da linguagem jurídica brasileira, entendida aqui como uma coleção complexa de hábitos linguísticos, que se desenvolveram ao longo de vários séculos, e que operadores do Direito usam de forma estratégica para atingir seus objetivos (TIERSMA, 1999). Hábito linguístico (jurídico), por sua vez, é caracterizado como sendo o uso ordinário da linguagem culta, terminológica, de sentenças extensas e complexas, redundâncias, latinismos,

3 Eventos comunicativos que auxiliam na determinação das estratégias de ação textual. 
construções impessoais, além de outros mecanismos de persuasão linguística, que funcionam "na prática e pela prática" ${ }^{4}$ e que remetem a um neologismo cada vez mais em uso no Brasil, o "juridiquês" (FRÖHLICH, 2014).

A abordagem desse tema foi idealizada por meio da observação de documentos jurídicos variados (portarias, ações, sentenças, despachos), analisados previamente por Fröhlich (ibidem). Dentro desse escopo, objetiva-se aqui discutir a matéria, sob o ponto de vista dos estudos da Linguística Forense, e sugerir, aos operadores do Direito, algumas atitudes em prol de uma redação jurídica mais objetiva, baseadas em reflexões dos pesquisadores Richard Wydick (1978), Valdeciliana de Andrade (2009), Michèle Asprey (2010), entre outros, que defendem que a linguagem jurídica tradicional pode não ser tão "segura" quanto parece.

\section{JURIDIQUÊS}

Os hábitos linguísticos, associados ao discurso burocrático, tornam a linguagem jurídica uma grande armadilha. De fato, as particularidades sintático-semânticas de documentos jurídicos, muitas vezes, estão diretamente associadas ao sucesso ou fracasso de muitos processos jurídicos, uma vez que a linguagem é comumente utilizada como ferramenta de persuasão e hegemonia linguística.

Exageros terminológicos (como o uso dos termos "carta política", "pretório", "acórdão guerreado" etc.), aliados a floreios (como o uso da locução latina $a b$ ovo) e itens lexicais exacerbados da língua culta (como "supedâneo", "despicienda" ou "abojada"), são encontrados em muitas peças jurídicas brasi-

4 Com alusão ao conceito de habitus do sociólogo francês Pierre Bourdieu que observa que o espaço do mundo social e de seus diversos campos é constituído pelo habitus, que não é "um sistema de formas e categorias universais, mas um sistema de esquemas incorporados que, constituídos no curso da história coletiva, são adquiridos ao longo da história individual e funcionam na prática e pela prática [...]" (BOURDIEU, 1979). 
leiras, que carecem de uma tradução intralingual ${ }^{5}$, ou seja, uma tradução para o próprio vernáculo.

A união de componentes complexos, como o uso de itens lexicais incomuns ao ideal canônico da língua portuguesa, faz com que a linguagem jurídica seja enquadrada como uma linguagem super especializada, denominada de "juridiquês". De fato, o termo juridiquês é caracterizado como o uso da linguagem jurídica de forma extrema e complexa, que se propõe, mesmo que inconscientemente, a persuadir e desorientar o leitor, com o uso de recursos linguísticos altamente terminológicos (como o uso de jargão profissional), muitas vezes arcaicos (como o uso extremo de latinismos), e de construções impessoais (como o uso de passivas), que despersonalizam o autor da fala, mas que, não raras as vezes, são vistos como necessários para validar o gênero do documento (como leis e códigos). Ele é defendido pelos juristas mais clássicos, com o argumento de que dessa forma não haveria lacunas de interpretação no texto, e odiado pelos vanguardistas, que prezam por uma linguagem jurídica mais limpa, clara e eficiente.

A procura por uma linguagem rebuscada e perfeita, associada à precisão de sentido, induz o jurista à formação de sentenças truncadas, evasivas, que podem levar à falsa interpretação. Nesse caso, forma-se um abismo linguístico, em que de um lado se encontra o profissional forense e do outro a população em geral. A linguagem permanece no centro, obscura e imperfeita aos olhos da concisão.

Dessa forma, o uso do juridiquês põe em xeque o ofício do operador do Direito, na medida em que este falha na exposição objetiva dos textos jurídicos, contrariando sua essência romana de interpretar/repassar as normas escritas aos cidadãos comuns. Como exemplo de juridiquês, Valdeciliana Andrade (2009, p.

5 Remetendo-nos aos ensinamentos do linguista russo, Roman Jakobson (1971), que considera a tradução intralingual, ou reformulação (rewording), uma interpretação dos signos verbais, por meio de outros signos da mesma língua.

6 Legalese, em inglês; Juristendeutsch, em alemão; e Jerga legal, em espanhol. 
3) cita alguns sinônimos para o termo "petição inicial", previsto pelo art. 282 do Código de Processo Civil: "peça atrial"; "peça preambular"; "peça autoral"; "peça prefacial"; "peça de arranque"; "peça preludial”; "peça primeva"; "peça primígena”; "peça exordial"; "peça gênese"; "peça inaugural"; "peça umbilical"; "peça vestibular"; "peça ovo", entre outras.

Por certo, pode-se julgar que tais exemplos são neologismos que afrontam a língua portuguesa, pois saem da esfera de meros sinônimos, utilizados para formar um texto coeso e coerente, e entram na esfera prolixa do discurso escrito. Não obstante, é consenso entre os pesquisadores da área, que a linguagem jurídica precisa ser clara. Há um termo clássico para designar o sentido que se deseja alcançar, qual seja "petição inicial”, que já faz parte do repertório terminológico jurídico.

Andrade (ibidem) menciona que um texto jurídico bem escrito deve conter "apenas o essencial, falar o que deve ser dito, argumentar com coerência e precisão, averiguar o veículo adequado da comunicação e vislumbrar o destinatário, sabendo que, muitas vezes, este nem sempre coincide com interpretante real". Com efeito, existe um postulado aceito no mundo jurídico de que "quanto mais rebuscado o texto, mais aceito pela sociedade forense ele é". Todavia, há um paradoxo nesse axioma, visto que para uma linguagem ser precisa, requisito da linguagem forense, ela deve ser clara, sucinta e exata.

Maria Carmen Guimarães Possato, em seu artigo online "As interfaces da linguagem jurídica" ${ }^{\text {, observa que as relações }}$ que se estabelecem entre o emissor e o destinatário não se desenvolvem, em todos os momentos do diálogo jurídico, na mesma direção. Existem duas vias de diálogo, sendo uma direcionada à comunicação mais aberta e outra à mais fechada. ${ }^{8}$ No caso da comunicação mais aberta, a mensagem é passada do jurista para o leigo (destinatário que normalmente não dispõe de formação jurídica), como é o caso de textos de leis, códigos e documentos jurídicos individuais. Portanto, a mensagem

7 Cf. http://freitasjus.blogspot.com.br._Último acesso em abril de 2014.

8 Baseado em Maria José Petri (PETRI, 2008). 
transita do iniciado para o não iniciado, circulando de forma aberta entre as partes.

Já em situação de comunicação mais fechada, a mensagem transita somente entre os operadores do Direito, ou seja, entre aqueles dotados de uma formação jurídica (de advogado para advogado, de advogado para juiz etc.). Dessa forma, a mensagem transita de iniciado para iniciado, circulando de forma fechada (PETRI, 2008), gerando certa tranquilidade ao redator. Essa "pseudo-segurança", frequentemente, gera uso despreocupado de juridiquês, situação na qual um possível destinatário externo, provavelmente, não seja levado em consideração. Não obstante, faz-se necessário observar que há situações nas quais documentos jurídicos saem da esfera estritamente forense (de jurista para jurista) e entram na esfera pública (de jurista para o leigo), como é o caso de cartas rogatórias, cujas peças processuais são traduzidas por intermediadores do Direito, considerados auxiliares da justiça, que, muitas vezes, são despreparados (leigos no assunto).

Além disso, é comum ouvir relatos de juristas contestando a prática do juridiquês, com o argumento de que nem mesmo eles (como doutores operadores do Direito) reconhecem e entendem por completo tudo que é dito/escrito nesse formato (FRÖHLICH, 2014).

\subsection{Hábitos linguísticos na linguagem jurídica}

Em complemento ao exposto, esta subseção aborda com mais detalhes alguns hábitos linguísticos, que colaboram na caracterização do juridiquês, que são recorrentes na linguagem jurídica brasileira, e que, somados, a tornam complexa e terminológica. Dentre eles, destacam-se a prolixidade, sentenças extensas e complexas, jargão jurídico, erros no original, construção impessoal e uso de latinismo. 


\subsubsection{Prolixidade (obstáculo sintático-semântico)}

Inicialmente considerada um fenômeno sintático, a prolixidade lida com a organização dos constituintes das frases. No entanto, suas características não necessariamente fazem referência a uma relação lógica entre as múltiplas combinações possíveis para transmitir um significado completo e compreensível $^{9}$, elas atingem também as esferas da semântica, que trata da relação entre os significantes do texto. A prolixidade, portanto, está ligada à complexidade técnica da língua, sendo um obstáculo sintático-semântico real aos destinatários.

Um dos motivos, ligados ao seu uso, pode estar associado à necessidade dos advogados de serem tão precisos e completos quanto possível, o que acaba promovendo o uso de vários itens lexicais semelhantes, bem como o reuso de frases inteiras utilizadas com sucesso anteriormente. Outra justificativa seria o uso do computador, que, dentre outras facilidades, possibilitou ainda mais o ato copy $\mathcal{E}$ paste de extratos de documentos passados, muitas vezes desconexos.

O uso de citações de outras ações é outro recurso adotado por vários advogados para justificarem seu pleito, em virtude do gênero ser o mesmo, acarretando em petições longas, repetitivas, muitas vezes sem nexo, e, por consequência, prolixas.

\subsubsection{Sentenças extensas e complexas}

O uso de sentenças com estruturas incomuns ao ideal canônico da língua portuguesa (sujeito-verbo-predicado) é um fator marcante nos textos jurídicos, principalmente nos legislativos, cuja estrutura codificada assume o lugar de estruturas coerentes e coesas. ${ }^{10}$ Segundo reflexões de Anna Christina Bentes, em seu artigo sobre linguística textual, "a situação comunicativa pode

9 Baseado no Dicionário Priberam da Língua Portuguesa. Disponível em: http:// www.priberam.pt. Último acesso em março de 2014.

10 Por estrutura coerente entende-se um texto formado com sentido, compatível com a situação comunicativa; e por estrutura coesa a manifestação linguística para atingir tal objetivo. 
contribuir fortemente para a construção de um ou de mais de um sentido global para o texto”. (BENTES, 2001).

Sob esse aspecto, as marcas linguísticas, como a pontuação fora do padrão, inclusão de vários apostos, bem como o uso repetitivo do verbo no gerúndio (por exemplo, "considerando o art. X, considerando o Decreto X, considerando a Lei X etc.”), entre o sujeito e o verbo, demarcam o estilo do gênero “portaria”, por exemplo, que por essência exprime uma ordem. Bentes (ibidem) reforça que o leitor ou destinatário de uma determinada produção textual ativa seu conhecimento do mundo, o que contribui para dar sentido global ao texto. Neste caso, é preciso ter conhecimento partilhado sobre o que está sendo focalizado, para então interpretar as palavras e/ou enunciados com sentido apropriado.

\subsubsection{Jargão jurídico (gíria profissional)}

O emprego de jargão é um recurso bastante usado na linguagem jurídica, tornando-se uma característica de economia linguística, uma vez que é utilizado, por grande parte dos operadores do Direito, para abreviar palavras e/ou expressões. Algumas amostras podem ser observas na relação abaixo:

$$
\begin{aligned}
& \text { C/C = "Cumulado Com" ou "Combinado Com" } \\
& \text { N.a. = "Nos autos" } \\
& \text { P.R.I. = "Publique-se, Registre-se, Intime-se" } \\
& \text { R. = "Referida" } \\
& \text { R.A. = "Registre-se. Autue-se" } \\
& \text { R.h. = "Recebi hoje" }
\end{aligned}
$$

Uma justificativa para o uso jargões (como o exemplo "R.h") seria o fato de serem comumente empregados em comunicação fechada, no entanto, é necessário relembrar que há situações nas quais documentos como esses saem da esfera estritamente forense (de jurista para jurista) e entram na esfera pública 
(de jurista para o público). Observa-se também que o jargão "R.h" acaba assumindo o lugar do título de certos documentos jurídicos (como no caso de despachos judiciais), apropriando-se de área de destaque na estrutura textual. Além disso, é comum que se use a sigla "R.h", que significa "recebido hoje", em documentos recebidos dias ou até meses antes, tornando a prática do seu uso questionável.

Não obstante, aceito ou não, o jargão tornou-se um recurso certamente particular de seu grupo, uma gíria profissional de difícil compreensão por comunidades externas, sendo os menos formais (como abreviaturas e recortes) raramente encontrados em textos doutrinais, seja em dicionários, glossários ou mesmo em livros didáticos da área, sinalizando para mais um ponto de dificuldade.

\subsubsection{Erros no original}

Mesmo não sendo uma propriedade muito discutida da linguagem jurídica, a presença de erros em documentos também pode representar um problema recorrente e, não raras as vezes, complexo. De fato, um erro importante não identificado pode prejudicar todo o processo, principalmente em se tratando da tradução de tais documentos (como no caso de cartas rogatórias). Segundo Francis Aubert (2012), existem vários tipos de erros no original. Dentre eles:

\section{Erros de digitação (slip of the finger);}

Erros como esses encontram-se na fronteira entre o banal e o sério e evidenciam falta de revisão do documento, deixando o texto confuso, o que prejudica seu entendimento.

\section{Erros de identificação;}

Essa modalidade de erro, por referir-se à identificação, pode constituir um dos elementos essenciais do texto. Segundo Aubert (ibidem), "qualquer alteração [na identificação] pode 
invalidar o documento ou, ao menos, tornar [uma possível] tradução inutilizável”. É o caso de erros em datas, nomes próprios, valores etc.

\section{Demais erros;}

Há diversas outras modalidades de erros e inadequações, como:

a) erro de informação factual (técnica, científica, econômica, política, geográfica, histórica, etc.);

b) erro de estrutura;

Envolve sintaxe, léxico e marcadores retóricos do texto, gerando, no limite, inconsistências lógicas, textuais e argumentativas, em graus variados de gravidade. Encontram-se, aqui, problemas de forma e conteúdo, porém, em um plano em que a incidência do erro não se situa na forma gráfica, nem nasce de descuidos com esta mesma forma.

c) erro de inadequação idiomática.

Esse tipo de erro é o mais complexo, uma vez que dificilmente tais inadequações deixarão de ter consequências para o sentido, tornando o texto mais obscuro ou mesmo ambíguo. Ele pode advir de textos originais escritos a várias mãos (comum em textos jurídicos) ou por não-nativos, e possui basicamente origem sintática, lexical e retórica.

\subsubsection{Construção impessoal}

O distanciamento provocado pelo uso de termos fixos, para nomear as funções de cada participante do processo, contribui para a impessoalidade. O uso de palavras como "autor" / "réu" / "advogado"/ "juiz" parece colaborar para um afastamento entre as partes. Uma das justificativas, segundo Ulrich Daum (2005), seria o receio de que haja diminuição da objetividade e imparcialidade nas relações entre os cidadãos e as autoridades judiciais (DAUM, 2005). 
A impessoalidade nos textos jurídicos também é observada no emprego de construções na passiva, como "vistos e examinados os autos" / "foi denunciado" / "foi recebida" / "foi interrogado" / etc., que dividem espaço (em um mesmo documento) com expressões pessoais, em primeira pessoa, como "recebo as petições" / "defiro o benefício da assistência judiciária gratuita" / "defiro expedição de ofício" / "nomeio tradutor", etc., que demarcam o poder de julgamento dos juízes.

A propósito, no caso da frase fixa "vistos e examinados os autos" ( $(\mathrm{v}+\mathrm{v}+$ sujeito paciente), há redução frasal, uma vez que se oculta tanto o verbo apassivador (ser), quanto a preposição (por ou de), que normalmente o segue. Sendo assim, essa frase não se enquadra na definição de voz passiva analítica (que se constitui com o verbo ser + particípio do verbo principal), tampouco de voz passiva sintética (constituída de verbo na $3^{3}$ pessoa, seguido do pronome apassivador se), demarcando mais uma particularidade da linguagem jurídica brasileira.

Destarte, sendo o discurso jurídico pessoal ou impessoal, é fato que a linguagem jurídica é especial, tornando-se desafiadora não apenas aos envolvidos diretamente com ela, mas também aos tradutores, auxiliares da justiça, nomeados para transportar para outro idioma todas as informações constantes num determinado documento jurídico.

\subsubsection{Latinismo (termo ou expressão em latim)}

O emprego de latinismos no Direito é um recurso recorrente, usado desde seu fundamento, não apenas na língua portuguesa, mas em todas aquelas ligadas ao Direito romano. No Brasil, a justiça, e por decorrência o Direito, começou a ser instalada em 1530, quando Martim Afonso de Souza recebeu amplos poderes de D. João III, Rei de Portugal, para, inclusive, sentenciar à morte autores de delitos considerados mais graves 
naquela época. ${ }^{11}$ Desde então, tem o Direito brasileiro o latim como seu fiel escudeiro.

Do ponto de vista gramatical, Mattoso Câmara (2002, p. 154) define latinismos como sendo "formas e construções de origem latina que não se adaptaram ao gênio da língua portuguesa. Os latinismos lexicais se distinguem dos vocábulos eruditos por se manterem dentro da estrutura mórfica latina inteiramente". Com efeito, por fazerem parte da história do Direito, alguns termos e expressões latinas (como habeas corpus, sic, ad hoc, ad referendum, caput), permanecem enraizados na linguagem jurídica brasileira, de tal forma que tornam-se parte integrante do vernáculo, peça-chave da jurisprudência. Petri e Ferraz (PETRI, 2008; JUNIOR, 1997), colocando-se a favor do uso de termos latinos no Direito, preconizam que o uso do latim traz ao texto brevidade e também clareza. De fato, sua utilização consciente e correta, com a finalidade de simplificar o sentido de tais termos, não cria obstáculos linguísticos ao texto e sim proporciona clareza textual. Muitos são os casos, porém, em que latinismos são empregados de forma incorreta ${ }^{12} \mathrm{e} / \mathrm{ou}$, mesmo que inconscientemente, para obscurecer o texto, acarretando na exclusão do entendimento por parte do público leigo.

Com base nessas observações, parece prudente pensar numa redação jurídica mais objetiva, orientada na aproximação do Poder Judiciário com o cidadão comum, conforme proposta da Associação dos Magistrados Brasileiros. ${ }^{13}$

11 Cf. http://www.tjrs.jus.br. Último acesso em abril de 2014.

12 Deve-se ficar atento ao uso gramatical da língua. No latim, a terminação das palavras é alterada conforme a função sintática que estas assumem dentro da oração, modificando-se conforme o caso (nominativo, acusativo, dativo, genitivo, ablativo e vocativo).

13 Seguindo o mote "ninguém valoriza o que não conhece", a AMB propôs em 2005 uma "reeducação linguística nos tribunais e nas faculdades de Direito, com o uso de uma linguagem mais simples, direta e objetiva", sendo este um dos "grandes desafios para que o Poder Judiciário fique mais próximo dos cidadãos" (http:// www.amb.com.br/index_asp?secao=campanha_juridiques, último acesso em março de 2014). 


\section{MOVIMENTO PLAIN LANGUAGE}

"Não podemos mais ignorar o fato de que a linguagem jurídica possa ser simplificada. Se não dispusermos de tempo e esforço para mudar nossos hábitos antigos, mais cedo ou mais tarde pagaremos a conta.

"A sociedade, os tribunais e os legisladores estão exigindo essa mudança e nossa própria integridade profissional depende disso.”

(ASPREY, 2010, p. 8)

Documentos jurídicos mais claros e sucintos é um desejo não só do público leigo, mas sim de um grande número de usuários e operadores do Direito, que há anos se movimentam em prol de uma linguagem jurídica simplificada. Esse movimento é conhecido internacionalmente por Plain Language (linguagem objetiva), que procura incentivar o poder público, bem como todos os juristas, ao uso mais consciente e sucinto da linguagem do Direito, a fim de democratizar os textos de documentos jurídicos por meio da descomplicação linguística.

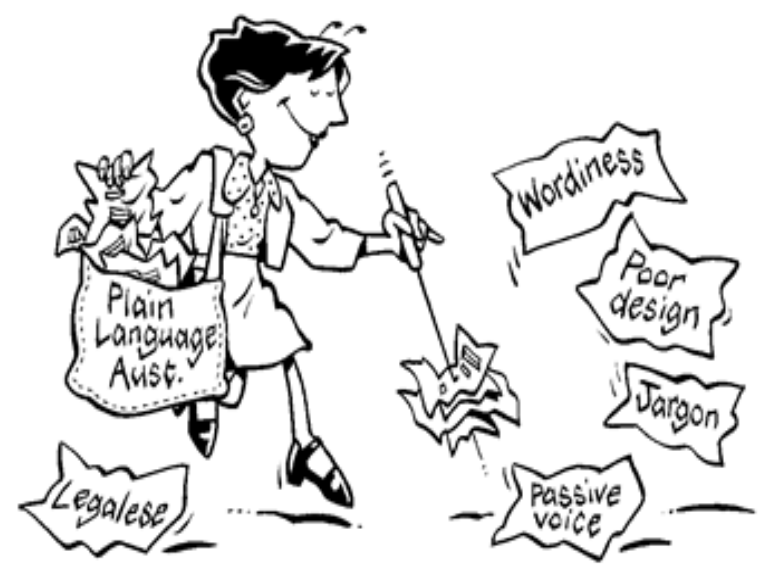

Figura 1: Ilustração do movimento Plain Language na Austrália. 
O movimento de simplificação da linguagem surgiu na década de 70 em países de língua inglesa (como Inglaterra, Estados Unidos e, com grande expressão, também na Austrália). Usava-se o termo Plain English para exprimir o uso de linguagem simples. Com o passar do tempo, porém, o movimento expandiu-se. Outros movimentos entraram em cena, como o Plain Swedish, movimento de simplificação da linguagem forense na Suécia. Gana, Índia, Nova Zelândia, Papua Nova Guiné, Singapura e África do Sul são países que também têm mostrado interesse no movimento (TIERSMA, 1999, p. 222).

Considerando a adesão crescente de outros países ao movimento, o termo Plain Language tornou-se mais democrático ${ }^{14}$, pois representa um termo de inclusão, que envolve outras línguas além da inglesa, com vistas a uma comunicação jurídica clara e objetiva, sem deixar de ser terminológica ou então sem precisão.

Mesmo não fazendo alusão direta ao movimento, essa interpretação é ratificada por pesquisadores brasileiros, como Eduardo Bittar (2010), que descreve:

[...] Simplificação não significa perda de técnica e nem insatisfação no aspecto precisão. Os excessos barrocos de linguagem, que são típicos da conformação retórica do direito, podem ser abolidos sem perda de critérios, mas no sentido de alcançar maior democratização do direito. A ideia da simplificação tem um sentido político, o da democratização do acesso ao direito, de um modo geral, na medida em que o direito não é um acervo de seus especialistas, um privilégio de alquimistas e iniciados, pois o direito opera na sociedade e para o povo (BITTAR, 2010, p 390).

Praticar plain language envolve, portanto, "ajustar" a linguagem forense para que todos envolvidos possam entender, de forma simples e clara, as informações contidas nos documentos jurídicos.

14 Mais detalhes em: http://www.plainlanguageaustralia.com. Último acesso em janeiro de 2014. 
Esse fato exige alteração da postura do operador do Direito que é normalmente envolvido por certos mitos. Dentre eles, destacam-se:

- Quanto mais "rebuscada" for a linguagem utilizada, mais reconhecida juridicamente ela será;

- se o operador do Direito não for extremamente formal, não será levado a sério;

- Se eu escrever em linguagem simples, serei mal interpretado;

- se eu não incluir os termos preestabelecidos, o documento não será aceito (como é o caso do uso de "vistos, etc." / "r.h." / P.R.I., entre outros);

- usar latinismos torna o documento mais "respeitável";

- usar linguagem extremamente técnica torna o texto legalmente mais confiável;

- não é possível escrever de maneira objetiva, sem perder a tecnicidade da linguagem jurídica;

- quanto maior o número de laudas, melhor é o trabalho e maior será a chance de sucesso;

- quanto menor o número de laudas, pior é o trabalho e menor será a chance de sucesso;

- não é possível mudar para escrita objetiva sem uma norma estabelecida;

- usar juridiquês é ser jurídico.

\subsection{Como quebrar o mito da invariância?}

Já em 1978 foi publicado nos Estados Unidos o livro Plain English for Lawyers, de Richard Wydick, que, segundo Tiersma (1999), teve grande influência na área. Ele cita quatro características marcantes da linguagem usada pelos advogados: prolixidade, obscuridade, pompa e estilo maçante. A partir dessas 
características, Wydick (1978) sugeriu que o operador do Direito tome uma série de atitudes em prol de uma linguagem jurídica mais objetiva. Dentre elas, destacam-se as seguintes:

- Omita palavras excedentes. Conforme Wydick (ibidem), existem dois tipos de palavras, as "working words", que carregam o sentido da frase, e as "glue words", que têm o objetivo de manter as "working words" juntas para fortalecer o sentido da frase. Se você encontrar muitas "glue words" é um sinal de que o seu texto foi mal construído.

Exemplo $_{1}$ Um julgamento com a presença de um júri foi solicitado pela defesa.

Neste exemplo, a frase apresenta sete "glue words" (um; com; a; de; um; foi; pela) e cinco "working words" (julgamento; presença; júri; solicitado; defesa). Além disso, há um estranhamento na frase por ela ter sido redigida na voz passiva. Wydick (ibidem) sugere, então, que, em casos semelhantes, se reorganize as "peças" da frase de forma mais compacta, diminuindo o número de "glue words".

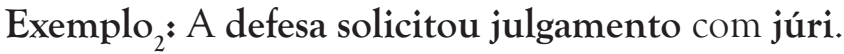

Com o uso da voz ativa, a ordem canônica (sujeito - verbo - predicado) foi reestabelecida e o número de "glue word" caiu de sete para dois $(A ; c o m)$. Essa é uma atitude estilística em prol de uma linguagem mais objetiva, uma vez que diminui o número de palavras da frase, contribuindo para a diminuição do número total de laudas do documento.

- Evite preposições compostas. Wydick (1978) sugere que se escolha sempre as formas mais simples de preposição, conforme as sugestões abaixo: 


\section{Inglês}

- at that point in time $=>$ then

- by means of $=>\boldsymbol{b} \boldsymbol{y}$

- by reason of $=>$ because of

- by virtue of $\Rightarrow$ by/under

- for the purpose of $=>$ to

- for the reason that $=>$ because

- from the point of view of $=>$ from/for

- in accordance with => by; under

- inasmuch as $=>$ since

- in connection with $=>$ with/ about, concerning

- in favor of $=>$ for

- in order to $=>$ to

- in relation to $=>$ about $/$ concerning

- in terms of $=>$ in

- in the event that $=>$ if

- on the basis of $=>$ by/from

- with a view to $=>$ to

- with reference to $=>$ about

- with regard to $=>$ about

- with respect $t=>$ on/about

\section{Português}

- naquele momento $=>$ quando

- por meio de $\Rightarrow$ por

- em razão de $=>$ por

- em virtude de $\Rightarrow$ devido a/por

- $\quad$ com a finalidade de $=>$ para

- pela razão de que $=>$ devido a/por

- do ponto de vista de $=>$ a partir de/por

- de acordo com $\Rightarrow$ conforme

- na medida em que $\Rightarrow$ dado que/ visto que/ porque

- em conexão $c o m=>$ com

- a favor de $\Rightarrow$ para

- a fim de $\Rightarrow$ para

- em relação $\mathrm{a}=>$ sobre

- em termos de $\Rightarrow$ em/ conforme

- no caso de $=>$ caso/ qua ndo

- com base em $=>$ segundo

- Tendo em vista $=>$ visando

- Com referência a $\Rightarrow$ sobre

- No que diz respeito a $\Rightarrow$ quanto a

- Em relação a => sobre

- Evite verborragia (prolixidade). Considerando a problemática envolvida com a prolixidade da linguagem jurídica, Wydick (1978) recomenda o uso de expressões mais objetivas, como as apresentadas abaixo:

\begin{tabular}{|c|c|}
\hline Verbose (prolixo) & Plain (objetivo) \\
\hline \multicolumn{2}{|c|}{ Inglês } \\
\hline $\begin{array}{l}\text { - } \quad \text { the fact that she had died } \\
\text { - } \quad \text { he was aware of the fact that } \\
\text { - despite the fact that } \\
\text { - } \quad \text { because of the fact that }\end{array}$ & $\begin{array}{ll}\text { - } & \text { her death } \\
\text { - } & \text { he knew that } \\
\text { - } & \text { although, even though } \\
\text { - } & \text { Because }\end{array}$ \\
\hline \multicolumn{2}{|c|}{ Port uguês } \\
\hline $\begin{array}{l}\text { - } \quad \text { o fato de que ela tinha morrido } \\
\text { - } \text { ele estava ciente do fato de que } \\
\text { - } \text { apesar do fato de que } \\
\text { - devido ao fato de }\end{array}$ & $\begin{array}{ll}\text { - } & \text { sua morte } \\
\text { - } & \text { ele sabia que } \\
\text { - } & \text { embora, apesar } \\
\text { - } & \text { Porque, devido a }\end{array}$ \\
\hline
\end{tabular}

- Encurte parágrafos e frases. Sempre que possível, encurte parágrafos e frases, conforme os exemplos abaixo: 
Exemplo: Enquanto o julgamento ainda estava em andamento, o juiz ordenou a retirada dos fotógrafos do recinto.

Exemplo $_{4}$ : Durante o julgamento, o juiz ordenou a retirada dos fotógrafos do recinto.

Com pequenos "ajustes", a frase exemplificada acima passou de dezesseis (exemplo 3) para doze palavras (exemplo 4), demarcando redução considerável de espaço. Richard Wydick (1978) sugere ainda:

- Não use frases jurídicas redundantes;

- use palavras familiares e concretas;

- use sentenças curtas;

- divida as sentenças longas e outras menores;

- use a voz ativa;

- organize a sua frase com cuidado (evite usar inversões para dar ênfase);

- mantenha o sujeito próximo ao verbo e o verbo próximo ao objeto;

- evite linguagem evasiva (pode distrair o leitor).

Sintonizada com as observações de Wydick, a pesquisadora Michèle Asprey, em seu livro "Plain Language for Lawyers" (ASPREY 2010), também faz várias sugestões para tornar o texto jurídico mais objetivo.

Segundo a autora, tenha sempre em mente alguns dos principais fundamentos para uma boa redação objetiva:

- Considere o seu leitor. Na redação objetiva, é preciso fazer mais do que apenas "traduzir" do juridiquês para plain language. Se fosse simples assim, usaríamos um único e definitivo dicionário. 
- Lembre-se que seu texto provavelmente terá uma audiência primária e uma secundária. É preciso pensar nas necessidades de ambas. Na dúvida, foque no leitor com maior dificuldade de entendimento.

- Foque no propósito. O que o seu leitor deseja com o documento? O que você, como escritor, quer fazer com o documento?

- Ajuste o nível de formalidade. Não tenha receio de usar a $1^{\text {a }}$ pessoa em sua redação, no entanto mantenha sempre uma postura profissional. Um bom escritor ajusta o "tom" do seu discurso de acordo com a sua audiência.

- Disponha as informações tendo em mente as necessidades do leitor envolvido, não as suas necessidades. Dê a seu público uma resposta e não uma dúvida (ganhei ou perdi?).

- Nunca escreva com raiva. Não esqueça, você é um agente neutro.

- Usar palavras objetivas não significa ser rude. Seja sempre cortês. A cortesia sempre foi um princípio fundamental de boa redação. Mas lembre-se, ser cortês não é ser pomposo.

Além desses fundamentos, Asprey (2010) sugere que o operador do Direito fique atento a certos pontos importantes da redação jurídica, como a estrutura, o vocabulário e a gramática.

\section{ESTRUTURA}

- Planeje suas atividades. Faça um diagrama, uma listagem ou apontamento com as informações principais, de acordo com a audiência e os propósitos do texto.

- Organize os pontos principais do texto. Qual é a parte mais importante do documento? Num julgamento, por exemplo, a parte mais importante é o veredito. Seja claro e objetivo ao fazê-lo. 
- Use frases curtas. Formule parágrafos curtos. Sentenças longas exigem tempo extra e maior cuidado com pontuação, além de deixar o leitor confuso.Não tenha medo de usar uma única frase no parágrafo. Se você usá-la com moderação e no lugar certo, ela pode ser muito efetiva. Ela vai atrair o olhar do leitor.

Também Valdeciliana Andrade (2009) discute a questão. Para a autora, todo parágrafo deve ter apenas uma ideia básica que deve ser expressa em uma frase. A frase que contém a ideia básica (tópico frasal) deve ser grafada no início do parágrafo (topicalização), pois, se alguém ler o texto superficialmente, lerá a primeira frase de cada parágrafo. Nesse caso, o autor do texto já terá cumprido seu objetivo comunicacional (ao menos em parte).

Já o parágrafo não deve ser longo, possuindo, no máximo, oito a dez linhas. Os parágrafos devem promover uma continuidade textual. Quando o leitor terminar de ler o texto, deve conseguir percorrer mentalmente os argumentos listados pelo autor. Assim, os parágrafos devem ser encadeados adequadamente. Empregue as relações textuais necessárias para promover a progressão textual e, dessa forma, a continuidade do que se está tratando no texto (ANDRADE, 2009).

- Fique atento à pontuação. Há um mito na escrita jurídica que diz que documentos jurídicos não precisam de pontuação para ser entendidos. Isso é um engano. Todo texto, independentemente se for jurídico ou não, precisa ser bem escrito. Lembre-se que a pontuação serve para dar clareza às informações.

\section{VOCABULÁRIO}

- Use termos técnicos com moderação. Usar termos técnicos na redação jurídica é aceitável quando o escritor esclarecer seu sentido ou estiver seguro de que "todos" os leitores estarão aptos a entendê-lo. 
- Não abuse dos sinônimos. É de responsabilidade do operador do Direito saber quando e como usar os sinônimos. No entanto, evite usar mais do que dois. A exemplo do termo "petição inicial" (peça ovo, peça vestibular, peça exordial, peça atrial, peça prologal, peça umbilical etc.).

- Atenção ao cluster de palavras. A maioria das "aglomerações” de palavras não são necessárias, podendo ser excluídas.

Exemplos: É importante notar que... / Antes de responder a sua pergunta, é necessário que... / É preciso levar em consideração que...

- Omita palavras arcaicas. Todos sabem quais são e que seria melhor não utilizá-las. Então, faça isso!

Exemplo: "Encaminhe o acusado ao ergástulo público, disse o juiz. Dois dias depois, a ordem ainda não havia sido cumprida porque ninguém sabia o significado de 'ergástulo' - palavra arcaica usada como sinônimo de cadeia" (Jornal do Senado, de 26.06.2012).

Outros exemplos: Alvazir de piso: juiz de primeira instância / Autarquia ancilar: Instituto Nacional de Previdência Social (INSS) / Caderno indiciário: inquérito policial / Cártula chéquica: folha de cheque / Consorte virago: esposa / Digesto obreiro: Consolidação das Leis do Trabalho (CLT) / Exordial increpatória: denúncia (peça inicial do processo criminal) / Repositório adjetivo: Código de Processo, seja Civil ou Penal.

\section{GRAMÁTICA}

- Opte pela voz ativa. Dê preferência à forma do presente, usando voz ativa nos seus textos.

Exemplos: Concluo que... / Determino que... 
- Evite uso de negação, mesmo que a frase não seja reduzida.

Exemplo: O secretário não pode registrar a ação sem o consentimento dos diretores. / O secretário só poderá registrar a ação com o consentimento dos diretores.

- Evite interromper a sentença com outras frases e parágrafos.

- Evite aposições muito longas.

Exemplo: Considerando isto, considerando aquilo...

- Evite o uso de termos desnecessários (como o pronome "Excelentíssimo", o adjetivo "Egrégio" e o título "Doutor").

- Evite usar expressões/jargões no papel de título em documentos como sentença e despachos. As expressões "R.h.", "Vistos etc." não devem assumir papel de destaque no documento.

Ademais, fale apenas o necessário, nada mais. Evite adjetivos exagerados. Evite as generalizações, mas não se prenda excessivamente aos detalhes de forma que o leitor possa perder o foco do que está sendo dito. Observe as normas gramaticais isso pode depor contra você.

\section{CONCLUSÃO}

É possível otimizar a redação jurídica, com foco nas interações e implicações sintáticas e semânticas do discurso escrito, por meio do uso mais consciente e objetivo da linguagem. Por certo, a linguagem objetiva é eficiente (economiza tempo, esforço, dinheiro e recursos naturais), efetiva (os leitores normalmente compreendem melhor e mais rapidamente documentos em 
plain language), pode dar competitividade e ainda pode melhorar a imagem do jurista, uma vez que os clientes tendem a valorizar a objetividade quando a reconhecem (ASPREY, 2010).

De fato, já estamos vivenciando algumas ações concretas de juristas brasileiros, como o Des. João Batista de Matos Danda (TRT/RS), que recentemente usou linguagem mais simples em um acórdão para mostrar que o judiciário pode efetivamente aproximar-se da população. Também a jurista Fátima Nancy Andrighi, Ministra do Superior Tribunal de Justiça, lançou em 2005 o projeto "Entenda a Decisão", que segue vinculado no seu site, oferecendo tradução intralingual de suas principais decisões. Seguindo o mote "ninguém valoriza o que não conhece", a Associação dos Magistrados Brasileiros (AMB) propôs, em 2005, uma "reeducação linguística nos tribunais e nas faculdades de Direito, com o uso de uma linguagem mais simples, direta e objetiva". No mesmo ano, a AMB lançou da cartilha "O Judiciário ao alcance de todos: Noções básicas de juridiquês" (AMB, 2007). Na sequência, o Tribunal de Justiça do Rio Grande do Sul lançou, em 2010, a campanha "Petição 10, Sentença 10", com o mote "O que importa é a qualidade e não a quantidade. Seja objetivo em suas petições”. Em 2013, o Tribunal de Justiça de São Paulo também aderiu a mesma campanha.

Com base nesses exemplos, e no que foi discutido ao longo deste trabalho, o que mais é possível fazer de concreto para tornar a linguagem jurídica mais objetiva? Por onde começar? A sugestão final é que, primeiramente, haja uma mudança de hábito pessoal. Pergunte-se: "Eu, investido do poder de julgar/ normatizar/defender, o que posso fazer para ser mais objetivo?". Faça, constantemente, exercícios mentais de mudança. Faça mudanças dentro do seu gabinete de trabalho. Oriente seus assessores, mostre a eles alguns exemplos e exija deles retorno concreto. Faça um modelo de sentença/acórdão/ petição próprio, dentro dos moldes aqui sugeridos.

Por que é preciso mudar? Como resposta, baseada no desenvolvimento deste trabalho, reporto-me às observações da 
advogada e pesquisadora, Michèle Asprey (2010), que argumenta que devemos mudar porque os velhos costumes estão mudando, assim como a percepção pública está mudando. Os juristas não são mais vistos como "guardiões eruditos de segredos desconhecidos" e o público leigo está exigindo o direito de entender as informações passadas a eles, bem como o direito de ler e entender o que é redigido em sua defesa.

\section{REFERÊNCIAS}

AMB. O judiciário ao alcance de todos - Noções básicas de juridiquês. Brasília: Associação dos Magistrados Brasileiros, 2007.

ANDRADE, V. O Juridiquês e a Linguagem Jurídica: o Certo e o Errado no Discurso. 2009. Último acesso em: maio de 2014. Disponível em: <http:// www.amatra17.org.br>.

AUBERT, F. H. Dúvidas e Controvérsias. Cadernos de Terminologia, n. 5, p. 05-43, 2012.

ASPREY, Michèle M. Plain Language for Lawyers. Sydney: The Federation Express, 2010.

BENTES, A. C. Introdução à Linguística 1, Domínios e Fronteiras. In: MUSSALIM, F.; BENTES, A. C. (Ed.). Linguística Textual. São Paulo: Cortez, 2001. p. 245-285.

BITTAR, E. C. B. Linguagem Jurídica. São Paulo: Saraiva, 2010.

CAMARA JUNIOR, M. Dicionário de Linguística e Gramática. Petrópolis: Vozes. 2002.

DAUM, U. Gerichts- und Behördenterminologie. Schriftenreihe des Sprachen und Dolmetscher-Instituts München, 2005.

FRÖHLICH, L. Tradução Forense: Um Estudo de Cartas Rogatórias e suas Implicações. 347 p. Tese (Doutorado) - Universidade Federal de Santa Catarina, 2014. Disponível em: http://www.pget.ufsc.br/curso/teses/ Luciane_Reiter_Frohlich_-_Tese.pdf.

HOLANDA, A. B. de. Novo Dicionário Aurélio. Rio de Janeiro: Nova Fronteira, 1986. 
JAKOBSON, R. Linguística e Comunicação. In: Aspectos Linguísticos da Tradução. São Paulo: Cultrix, 1971, p. 63-72.

JUNIOR, T. F. Direito, Comunicação e Retórica. São Paulo: Saraiva, 1997.

NUNES, R. (Ed.). Manual de Introdução ao Estudo do Direito. São Paulo: Saraiva, 2006.

PETRI, M. J. C. Manual de linguística jurídica. São Paulo: Saraiva, 2008.

TIERSMA, P. M. Linguistic Issues in the Law. Language, Linguistic Society of America. V. 69, N. 1, p. 113-137, 1993.

TIERSMA, P. M. Legal Language. Chicago: Chicago Press, 1999.

TORRES, S.; ALMEIDA, M. B. de. Documentação Jurídica: Reflexões sobre a Função Social do Documento Legislativo. In: Anais do II Congresso Brasileiro em Representação e Organização do Conhecimento, FGV, Rio de Janeiro, 2013.

WYDICK, Richard C. Plain English for Lawyers [1978]. In: California Law Review. Vol. 66, N. 4. Disponível em:<http://scholarship.law.berkeley.edu/ cgi/viewcontent. cgi?article $=2362 \&$ context $=$ californialawreview $>$.

Artigo recebido em 20/08/2015

Artigo aprovado em 28/08/2015 